\title{
Nanoscale surface compositions and structures influence boron adsorption properties of anion exchange resins
}

\author{
G. N. Manjunatha Reddy, ${ }^{1}$ Jeffrey A. Gerbec, ${ }^{2}$ Fumihiko Shimizu, ${ }^{3}$ Bradley F. Chmelka ${ }^{1, *}$ \\ ${ }^{1}$ Department of Chemical Engineering, University of California, Santa Barbara, California, \\ 93106, U.S.A. \\ ${ }^{2}$ Mitsubishi Chemical-Center for Advanced Materials, University of California, Santa Barbara, \\ California, 93106, U.S.A. \\ ${ }^{3}$ Science and Innovation Center, Mitsubishi Chemical Corporation, Yokohama-shi, Kanagawa \\ 227-8502, Japan
}

\section{Electronic Supplementary Information}

\section{Table of contents}

1. Inductively-Coupled-Plasma atomic emission spectroscopy of a NMDG-functionalized resin

2. $1 D^{15} \mathrm{~N}\left\{{ }^{1} \mathrm{H}\right\}$ DNP-NMR spectra of NMDG and boron-adsorbed NMDG-functionalized resin

3. $1 \mathrm{D}^{11} \mathrm{~B}\left\{{ }^{1} \mathrm{H}\right\} \mathrm{CP}-\mathrm{MAS}$ NMR spectra of boron-adsorbed NMDG-functionalized resin

4. Solid-state $1 \mathrm{D}{ }^{1} \mathrm{H}, 2 \mathrm{D}{ }^{13} \mathrm{C}\left\{{ }^{1} \mathrm{H}\right\}$ HETCOR and $2 \mathrm{D}{ }^{1} \mathrm{H}\left\{{ }^{1} \mathrm{H}\right\}$ DQ-SQ correlation NMR spectra of NMDG, PSDVB resin, and NMDG-functionalized resin

5. XPS analyses of different batches of boron-adsorbed NMDG-functionalized resins

6. $1 \mathrm{D}^{15} \mathrm{~N}\left\{{ }^{1} \mathrm{H}\right\}$ DNP-NMR spectra of different batches of boron-adsorbed NMDG-functionalized resins

7. Boron adsorption behaviors of different batches of NMDG-functionalized resins

8. Solid-state $2 \mathrm{D}{ }^{11} \mathrm{~B}\left\{{ }^{1} \mathrm{H}\right\}$ and ${ }^{13} \mathrm{C}\left\{{ }^{1} \mathrm{H}\right\}$ correlation NMR spectra of different NMDGfunctionalized resins. 


\section{Inductively-Coupled-Plasma atomic emission spectroscopy of NMDG-functionalized PSDVB resins}

Table S1. Elemental concentrations of metal ions in NMDG-functionalized resins

\begin{tabular}{ccc}
\hline $\begin{array}{c}\text { Concentration } \\
\text { (Equivalents) }\end{array}$ & \multicolumn{2}{c}{ NMDG-functionalized resin } \\
$\mathrm{B}$ & $<1$ & After boron exposure \\
$\mathrm{Na}$ & $<10$ & 2500 \\
$\mathrm{Mg}$ & $<1$ & $<10$ \\
$\mathrm{Al}$ & $<1$ & $<1$ \\
$\mathrm{Ca}$ & $<10$ & $<1$ \\
$\mathrm{Fe}$ & $<10$ & $<10$ \\
$\mathrm{Ni}$ & $<1$ & $<10$ \\
$\mathrm{Zn}$ & $<1$ & $<1$ \\
\hline
\end{tabular}

Upon treatment with Millipore water, the ${ }^{11} \mathrm{~B}$ signal originate from the mono-chelate complex was observed to be less intense relative to the ${ }^{11} \mathrm{~B}$ signal from the bis-chelate complex. This is attributed to relatively weak affinity interactions of borate anions in mono-chelate complexes in comparison to the borate anions in bis-chelate complexes. The borate anions in mono-chelate are thus more likely to exchange with counter ions in aqueous solutions as previously observed by Davis and coworkers, for example, in guanosine borate gels [Refs. 40 and 41 of the main paper]. 


\section{2. $1 D^{15} \mathbf{N}\left\{{ }^{1} \mathrm{H}\right\}$ DNP-MAS NMR spectra of boron-adsorbed NDMG-functionalized resins and precursor species.}

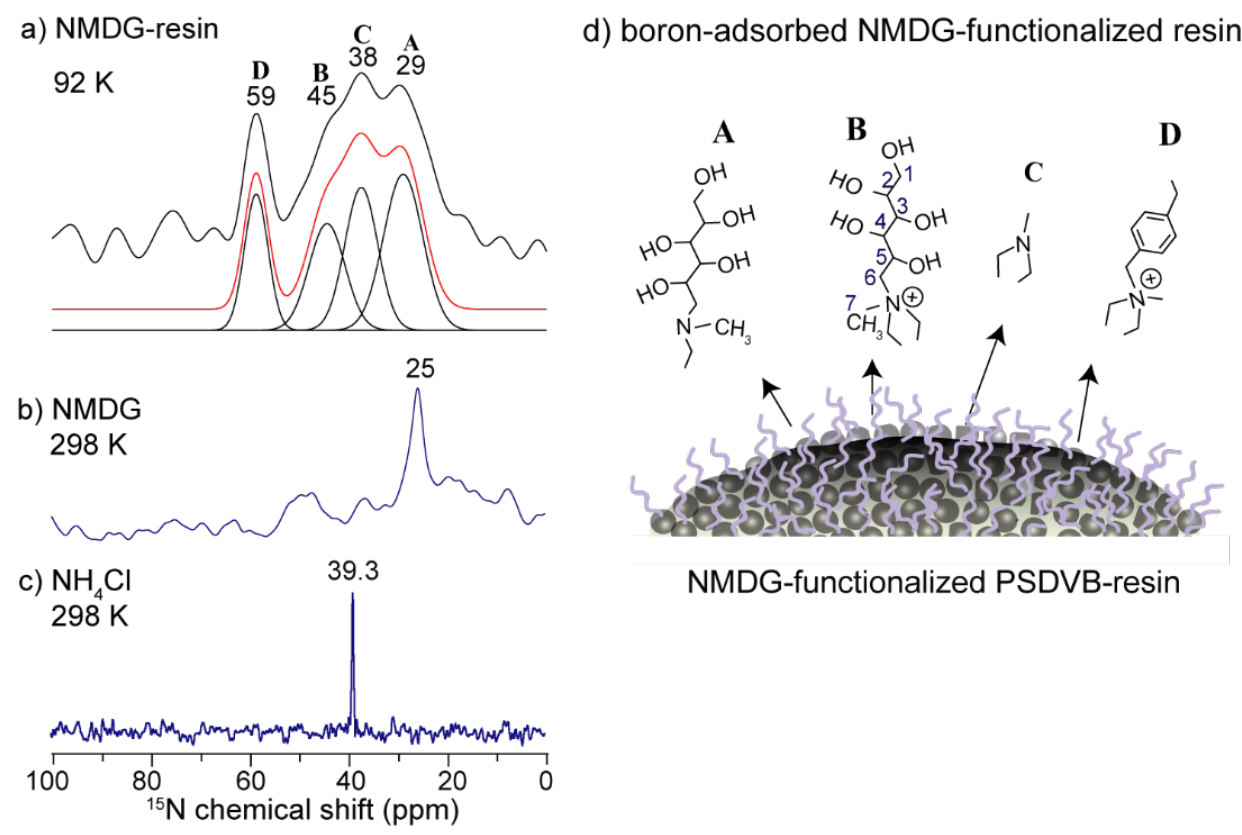

Figure S1. Surface-enhanced 1D ${ }^{15} \mathrm{~N}\left\{{ }^{1} \mathrm{H}\right\}$ DNP-MAS NMR spectra acquired at $9.4 \mathrm{~T}, 92 \mathrm{~K}$, and $8 \mathrm{kHz}$ MAS, with a CP contact time of $2 \mathrm{~ms}$ and using $16 \mathrm{mM}$ TEKPol in 1,1,2,2-tetrachloroethane on (a) NMDG-functionalized ion-exchange resin acquired using 16384 co-added transient and a relaxation delay of $4 \mathrm{~s}$ corresponding to a total experimental time of $18 \mathrm{~h}$ and (b) NMDG acquired using 8192 co-added transients and a relaxation delay of $4 \mathrm{~s}$ corresponding to a total experimental time of $9 \mathrm{~h}$. (c) Conventional 1D ${ }^{15} \mathrm{~N}\left\{{ }^{1} \mathrm{H}\right\}$ CP-MAS NMR spectra of powdered $\mathrm{NH}_{4} \mathrm{Cl}$ acquired under similar conditions, though at $298 \mathrm{~K}$, using 512 co-added transients and a CP contact time of $1 \mathrm{~ms}$ and relaxation delay of $4 \mathrm{~s}$ corresponding to a total experimental time of $35 \mathrm{~m}$. ${ }^{15} \mathrm{~N}$ signal assignments of surface species $\mathbf{A}, \mathbf{B}, \mathbf{C}$, or $\mathbf{D}$ are labelled as indicated in (d) the schematic diagram of the functional groups on the resin surface.

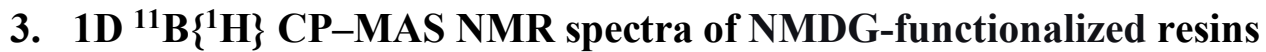
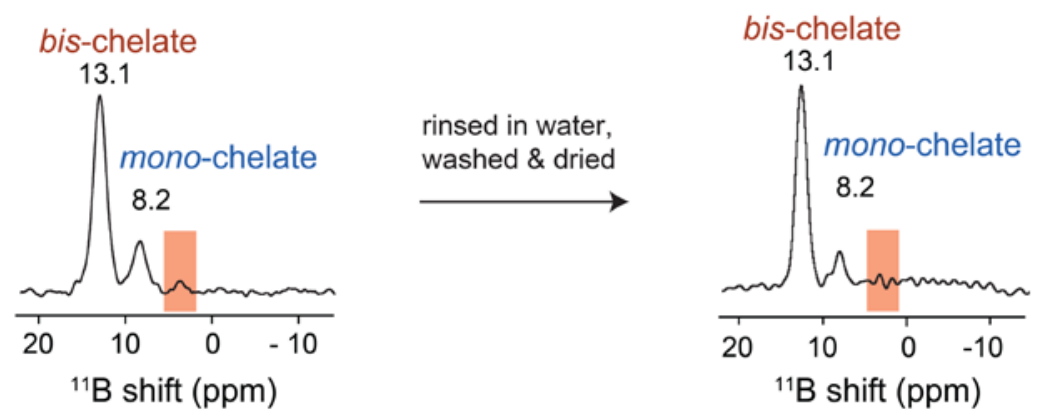

Figure S2. Solid-state 1D ${ }^{11} \mathrm{~B}\left\{{ }^{1} \mathrm{H}\right\}$ CP-MAS NMR spectra acquired at $11.7 \mathrm{~T}$ and at room temperature of NMDG-functionalized resins containing adsorbed boron (a) before and (b) after washing with ultrapure water. Assignments of borate mono- $(8.2 \mathrm{ppm})$ and bis-chelate (13.1 ppm) complexes and non-covalently bound boron atoms $(3.2 \mathrm{ppm})$ are labeled above the respective signals or by the shaded bands. 


\section{Solid-state 1D ${ }^{1} \mathrm{H}, 2 \mathrm{D}{ }^{13} \mathrm{C}\left\{{ }^{1} \mathrm{H}\right\}$ HETCOR and $2 \mathrm{D}{ }^{1} \mathrm{H}\left\{{ }^{1} \mathrm{H}\right\}$ DQ-SQ correlation NMR spectra of NMDG, PSDVB resin, and NMDG-functionalized resin}

(a) $\mathrm{N}$-methyl-D-glucamine

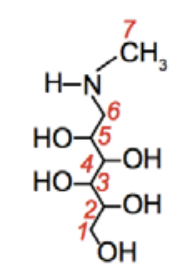

(b) Poly(styrenedivinylbenzene)
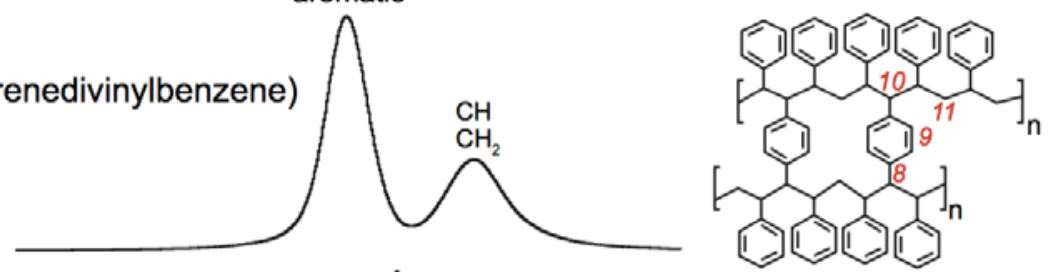

(c) Boron-adsorbed NMDG resin
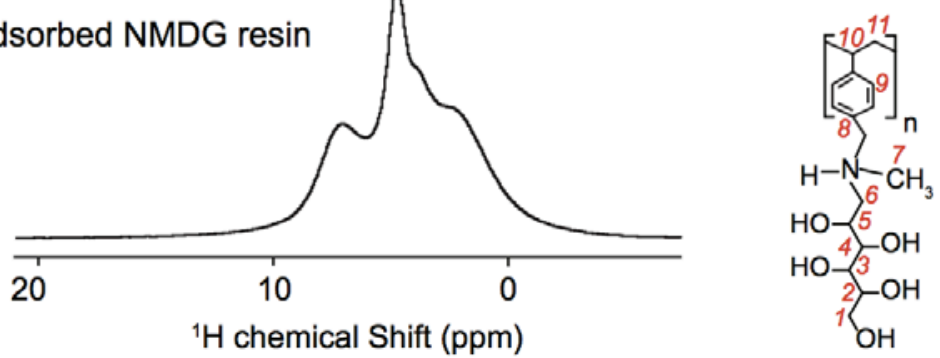

Figure S3. Solid-state 1D ${ }^{1} \mathrm{H}$ MAS NMR spectra acquired at $11.7 \mathrm{~T}, 298 \mathrm{~K}$, and $60 \mathrm{kHz}$ MAS of (a) NMDG, (b) PSDVB resin, and (c) boron-adsorbed NMDG-functionalized PSDVB resin. Assignments of ${ }^{1} \mathrm{H}$ signals associated with alkyl and aromatic groups are indicated that are accompanied by the schematic structure figures (right).

Dipole-dipole-coupled ${ }^{13} \mathrm{C}-{ }^{1} \mathrm{H}$ moieties can be distinguished and identified by recording 2D ${ }^{13} \mathrm{C}\left\{{ }^{1} \mathrm{H}\right\}$ heteronuclear correlation (HETCOR) NMR spectra at different $\mathrm{CP}$ contact times. Improved resolution is achieved in the indirect ${ }^{1} \mathrm{H}$ dimension of the $2 \mathrm{D}{ }^{13} \mathrm{C}\left\{{ }^{1} \mathrm{H}\right\}$ HECTOR spectra of NMDG (Figure S4), which enabled different ${ }^{1} \mathrm{H}$ signals to be distinguished and assigned. In particular, strong intensity correlations associated with dipole-dipole-coupled ${ }^{13} \mathrm{C}-{ }^{1} \mathrm{H}$ moieties in the $2 \mathrm{D}{ }^{13} \mathrm{C}\left\{{ }^{1} \mathrm{H}\right\}$ HETCOR spectrum of NMDG (Figure S4a) acquired using a short $0.1 \mathrm{~ms}$ contact time establishes spatial proximities of ${ }^{13} \mathrm{C}-{ }^{1} \mathrm{H}$ pairs in terminal $-\mathrm{NCH}_{3}(C 738 \mathrm{ppm}$ and $H 71.2$ ppm), $-\mathrm{NCH}_{2}$ (C6 $56 \mathrm{ppm}$ and $\left.{ }^{1} \mathrm{H} 1.5 \mathrm{ppm}\right)$, central $-\mathrm{CH}-(C 274, C 368, C 4-571 \mathrm{ppm}$ and $H 2-5$ $2.6 \mathrm{ppm})$ groups and $-\mathrm{CH}_{2} \mathrm{OH}\left(\mathrm{Cl} 62 \mathrm{ppm}\right.$ and $\left.{ }^{1} \mathrm{H} 1.5 \mathrm{ppm}\right)$ moieties. In addition, 2D correlation intensities between ${ }^{13} \mathrm{C}$ signals $(C 2-C 6)$ and ${ }^{1} \mathrm{H}$ signal at $4.2 \mathrm{ppm}$ indicate close proximities between carbon atoms and hydroxyl groups. A $2 \mathrm{D}{ }^{13} \mathrm{C}\left\{{ }^{1} \mathrm{H}\right\}$ HETCOR spectrum of NMDG was acquired under identical conditions, except using a longer $2 \mathrm{~ms}$ contact time (Figure S4b); it establishes spatial proximities of ${ }^{13} \mathrm{C}-{ }^{1} \mathrm{H}$ pairs between central carbon atoms and $-\mathrm{NH}(6.5 \mathrm{ppm})$ groups and central carbon atoms and $\mathrm{OH}$ groups $(8.1 \mathrm{ppm})$ moieties. The high ppm value of $\mathrm{OH}$ $(8.1 \mathrm{ppm})$ is attributed to strong hydrogen-bonding interactions between hydroxyl groups of neighboring NMDG moieties. Notably, ${ }^{1} \mathrm{H}$ chemical shifts of $-\mathrm{OH}(4.5 \mathrm{ppm}),-\mathrm{NH}(6.1 \mathrm{ppm})$ and hydrogen-bonded $-\mathrm{OH}$ groups $(8.1 \mathrm{ppm})$ are clearly resolved in the ${ }^{1} \mathrm{H}$ dimension of the $2 \mathrm{D}$ ${ }^{13} \mathrm{C}\left\{{ }^{1} \mathrm{H}\right\}$ HETCOR spectrum. 

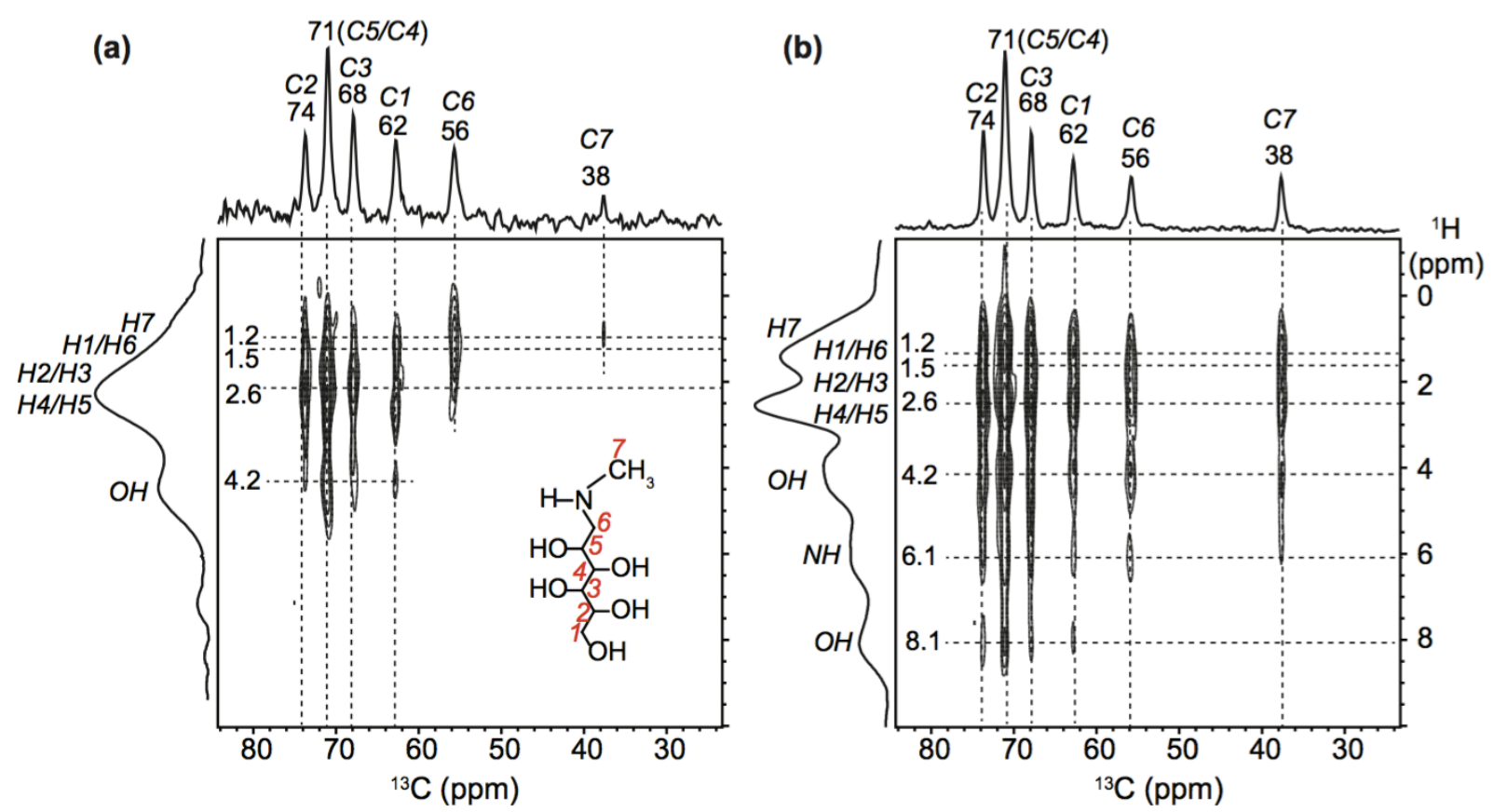

Figure S4. 2D ${ }^{13} \mathrm{C}\left\{{ }^{1} \mathrm{H}\right\}$ HETCOR NMR spectra of $N$-methyl- $D$-glucamine, which were recorded at $11.7 \mathrm{~T}$, room temperature, $12.5 \mathrm{kHz} \mathrm{MAS}$, and with a CP contact time of (a) $0.1 \mathrm{~ms}$ or (b) $2 \mathrm{~ms}$. Projections of the $2 \mathrm{D}{ }^{13} \mathrm{C}$ and ${ }^{1} \mathrm{H}$ intensities are shown along the top horizontal and left vertical axes, respectively. Dashed lines depict the ${ }^{13} \mathrm{C}-{ }^{1} \mathrm{H}$ signal assignments, with numbering as shown in the accompanying schematic diagram.

Concurrently, correlated 2D intensities observed in the 2D ${ }^{13} \mathrm{C}\left\{{ }^{1} \mathrm{H}\right\}$ HETCOR NMR spectrum of PSDVB resin (Figure S5a) acquired using a short contact time of $0.1 \mathrm{~ms}$ are characteristic of dipole-dipole couplings between directly bonded ${ }^{13} \mathrm{C}-{ }^{1} \mathrm{H}$ pairs; correlated signals of $C 10$ (41 ppm), $C 11(47 \mathrm{ppm})$ and ${ }^{1} \mathrm{H}$ signals of $1.5 \mathrm{ppm}$ correspond to vinyl $-\mathrm{CH}$ and $-\mathrm{CH}_{2}$ groups, and between ${ }^{13} \mathrm{C}$ signals of $C 9$ at $129 \mathrm{ppm}$ and ${ }^{1} \mathrm{H}$ signals at $6.7 \mathrm{ppm}$ originate from benzyl groups. In the 2D ${ }^{13} \mathrm{C}\left\{{ }^{1} \mathrm{H}\right\}$ HETCOR NMR spectrum (Figure S5b) of PSDVB resin acquired using a longer contact time of $2 \mathrm{~ms}$, correlated 2D intensities between $C 10(41 \mathrm{ppm}), C 11(47 \mathrm{ppm})$ and aromatic ${ }^{1} \mathrm{H}$ signals of $6.7 \mathrm{ppm}$ and between $C 9$ carbon atoms $(129 \mathrm{ppm})$ and ${ }^{1} \mathrm{H}$ signals vinyl $-\mathrm{CH}$ and $-\mathrm{CH}_{2}$ groups, and between ${ }^{13} \mathrm{C}$ signals at $129 \mathrm{ppm}$ and ${ }^{1} \mathrm{H}$ signals at $6.7 \mathrm{ppm}$ originate from benzyl groups at $1.5 \mathrm{ppm}$ are observed, which indicate long-range dipole-dipole interactions between aromatic and vinyl groups of PSDVB resin. These 2D correlated intensities establish that the aromatic carbon atoms are spatially proximate $(<1 \mathrm{~nm})$ to the benzylic and methylene hydrogen atoms. Analyses of 2D ${ }^{13} \mathrm{C}\left\{{ }^{1} \mathrm{H}\right\}$ HETCOR NMR spectra of NMDG and PSDVB provide an indispensable basis to separate to distinguish and identify 2D correlation intensities in the analogues HETCOR spectra of boron-adsorbed NMDG-resin acquired using short $(0.1 \mathrm{~ms})$ and long $(2 \mathrm{~ms})$ of contact times, as shown in Figure S6, which will be discussed in the next section. 

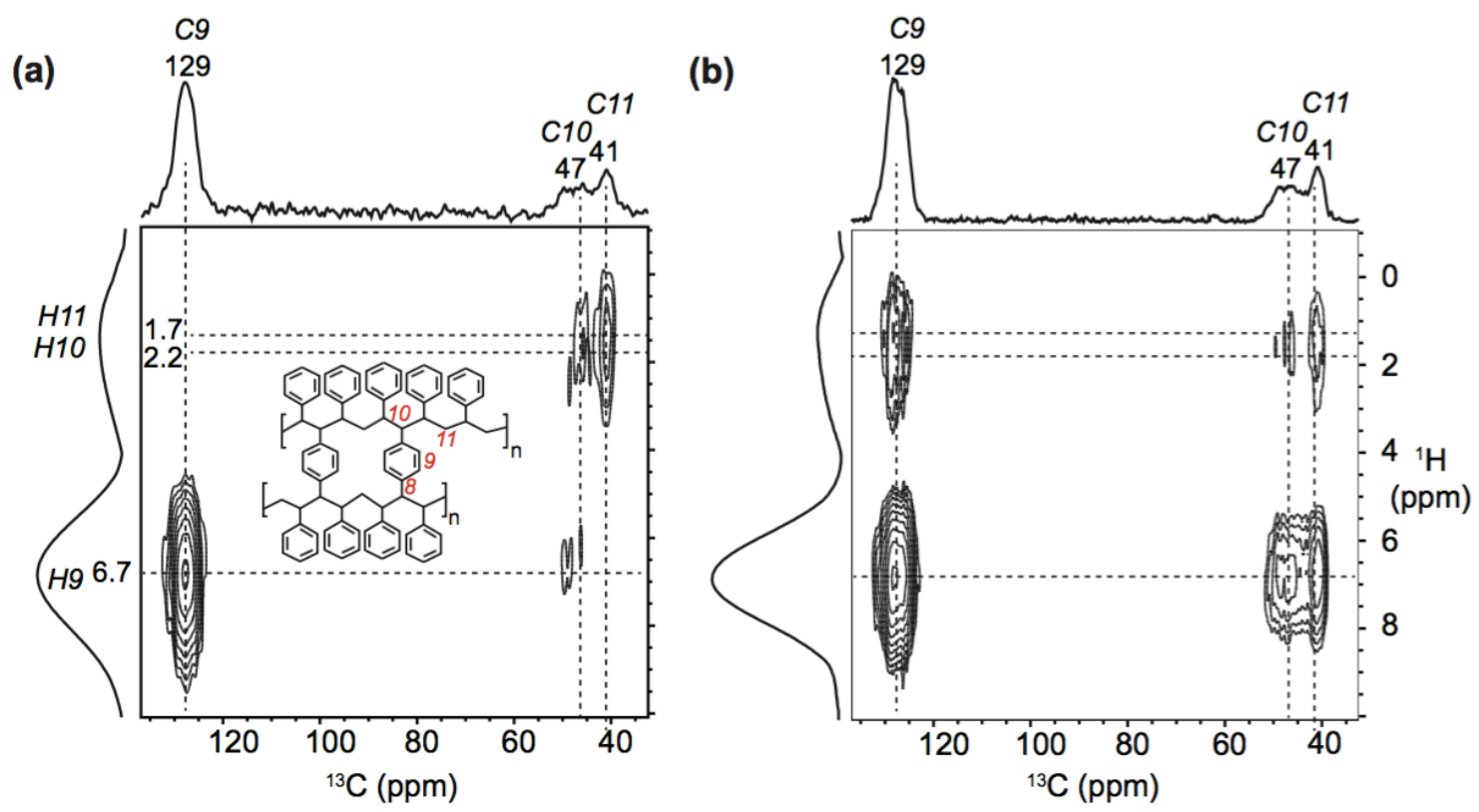

Figure S5. 2D ${ }^{13} \mathrm{C}\left\{{ }^{1} \mathrm{H}\right\}$ HETCOR NMR spectra of PSDVB, which were acquired at $11.7 \mathrm{~T}, 298$ $\mathrm{K}, 12.5 \mathrm{kHz} \mathrm{MAS}$, and with a CP contact time of (a) $0.1 \mathrm{~ms}$ or (b) $2 \mathrm{~ms}$. Projections of ${ }^{13} \mathrm{C}$ and ${ }^{1} \mathrm{H}$ spectra are shown along the top horizontal and left vertical axes, respectively. Dashed lines depict the ${ }^{13} \mathrm{C}-{ }^{1} \mathrm{H}$ signal assignments.

To gain insight into the local structures of chelate complexes and mutual interactions between boron atoms and the functional groups on the resin particle surface, $2 \mathrm{D}{ }^{13} \mathrm{C}\left\{{ }^{1} \mathrm{H}\right\} \mathrm{HETCOR}$ NMR and ${ }^{1} \mathrm{H}\left\{{ }^{1} \mathrm{H}\right\}$ DQ-SQ correlation spectra of a boron-adsorbed NMDG-functionalized PSDVB resin was analyzed and compared (Figures S6 and S7). In the 2D ${ }^{13} \mathrm{C}\left\{{ }^{1} \mathrm{H}\right\}$ HETCOR spectrum recorded using a short recouping time of $0.1 \mathrm{~ms}$, broad distributions of ${ }^{13} \mathrm{C}$ NMR signals at $40-45 \mathrm{ppm}(C 10$, C11) and ${ }^{13} \mathrm{C}$ NMR signals at $1.2-2.2 \mathrm{ppm}$ (H1O, H11) originate from the vinyl groups, and distributions of correlations between ${ }^{13} \mathrm{C}$ signals in the range $125-135 \mathrm{ppm}(C 9)$ and ${ }^{1} \mathrm{H}$ signals at $6.7 \mathrm{ppm}$ correspond to aromatic groups of the PSDVB resin, respectively. Whereas, a broad distribution of $2 \mathrm{D}$ correlations between ${ }^{13} \mathrm{C}$ signal intensities in the range $60-75 \mathrm{ppm}(\mathrm{Cl}-\mathrm{C} 6)$ and ${ }^{1} \mathrm{H}$ signals in the range $2.2-4.1$ (H1-HO) ppm is attributed to the directly bonded ${ }^{13} \mathrm{C}-{ }^{1} \mathrm{H}$ pairs in the of the surface-grafted NMDG groups on the PSDVB resin. By comparison, $2 \mathrm{D}{ }^{13} \mathrm{C}\left\{{ }^{1} \mathrm{H}\right\}$ HETCOR spectrum recorded using a short recouping time of $2 \mathrm{~ms}$ exhibited correlated 2D intensities stemming from long-range ${ }^{13} \mathrm{C}$ - ${ }^{1} \mathrm{H}$ dipole-dipole interactions between NMDG surface functional groups and the PSDVB resin. For example, distributions of 2D correlation intensities between ${ }^{13} \mathrm{C}$ signals in the range of $60-75 \mathrm{ppm}$ and ${ }^{1} \mathrm{H}$ signals at $6.7 \mathrm{ppm}$, and between ${ }^{13} \mathrm{C}$ signals at $125-135 \mathrm{ppm}$ and ${ }^{1} \mathrm{H}$ signals at $2.2-4.1 \mathrm{ppm}$ indicate the close proximities $(<1 \mathrm{~nm})$ between NMDG surface functional groups and PSDVB resin. In particular, subltle differences and broad distributions of correlated 2D intensities of ${ }^{13} \mathrm{C}-{ }^{1} \mathrm{H}$ moieties in surface-grafted NMDG moieties (Figure S6a) in comparison to the analogue 2D correlations of NMDG moieties (Figure S4a) is attributed to the surface heterogeneity associated with grafted NMDG moieties on the PSDVB resin. In addition, the absence of ${ }^{13} \mathrm{C}-{ }^{1} \mathrm{H}$ correlated $2 \mathrm{D}$ intensities between NMDG carbon atoms $(\mathrm{Cl}-\mathrm{C} 5,60-57 \mathrm{ppm})$ and hydrogen bonded protons of hydroxyl groups $(\mathrm{OH}, 8.1 \mathrm{ppm})$ is due to the lack of hydroxyl groups upon the formation of boron chelate complexes. 

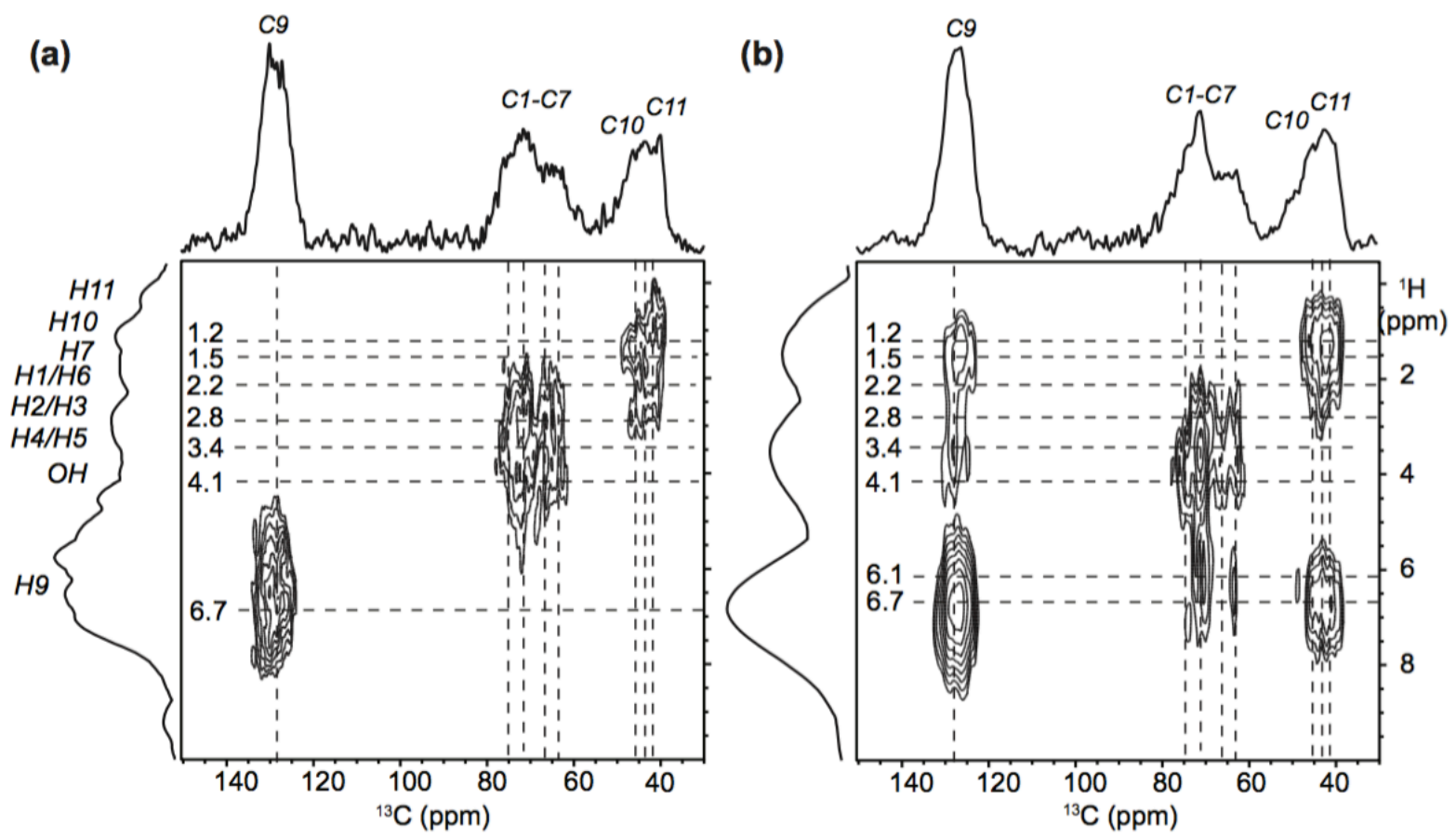

Figure S6. 2D ${ }^{13} \mathrm{C}\left\{{ }^{1} \mathrm{H}\right\}$ HETCOR NMR spectra of boron-adsorbed PSDVB-NMDG-resin, which were recorded at $11.7 \mathrm{~T}$, room temperature, $12.5 \mathrm{kHz}$ MAS, and with a CP contact time of (a) 0.1 $\mathrm{ms}$ or (b) $2 \mathrm{~ms}$. Projections of ${ }^{13} \mathrm{C}$ and ${ }^{1} \mathrm{H}$ spectra are shown along the top horizontal and left vertical axes, respectively. Dashed lines depict assignments of $2 \mathrm{D}{ }^{13} \mathrm{C}-{ }^{1} \mathrm{H}$ correlation intensities.

Molecularly proximate and dipole-dipole-coupled ${ }^{1} \mathrm{H}-{ }^{1} \mathrm{H}$ pairs can be probed by analyzing 2D ${ }^{1} \mathrm{H}\left\{{ }^{1} \mathrm{H}\right\}$ double-quantum - single-quantum (DQ-SQ) correlation NMR spectra of NMDG functional groups, PSDVB resin, and boron-adsorbed NMDG-functionalized PSDVB resins (Figure S7). In the 2D ${ }^{1} \mathrm{H}$ DQ-SQ NMR spectrum of NMDG (Figure S7a, gray color dots), selfcorrelation intensities correspond to $\mathrm{CH}_{2}(\mathrm{SQ}=1.2$ and $\mathrm{DQ}=2.4 \mathrm{ppm}), \mathrm{NCH}_{3}(\mathrm{SQ}=1.5$ and $\mathrm{DQ}$ $=3.0 \mathrm{ppm}), \mathrm{NCH}_{2}(\mathrm{SQ}=2.6$ and $\mathrm{DQ}=5.2 \mathrm{ppm})$ and $\mathrm{NH}(\mathrm{SQ}=4.2$ and $\mathrm{DQ}=8.2 \mathrm{ppm})$ and $\mathrm{NH}$ $\left(\mathrm{SQ}=6.1\right.$ and $\mathrm{DQ}=12.2 \mathrm{ppm}$ ) moieties, and cross-correlated 2D intensities associated with $\mathrm{NCH}_{3}$ and $\mathrm{NH}(\mathrm{DQ}=6.0 \mathrm{ppm}), \mathrm{NCH}_{2}$ and $\mathrm{NH}(\mathrm{DQ}=7.1 \mathrm{ppm})$ are observed (Table $\left.\mathrm{S} 2\right)$. By comparison, in the $2 \mathrm{D}{ }^{1} \mathrm{H}$ DQ-SQ NMR spectrum of PSDVB resin (Figure S7b, green color dots), selfcorrelation intensities at $\mathrm{SQ}=1.7$ and $\mathrm{DQ}=3.4 \mathrm{ppm}, \mathrm{SQ}=2.2$ and $\mathrm{DQ}=4.4 \mathrm{ppm}$ and $\mathrm{SQ}=6.7$ and $\mathrm{DQ}=13.4 \mathrm{ppm}$ correspond to ${ }^{1} \mathrm{H}-{ }^{1} \mathrm{H}$ proximities in vinyl and aromatic groups. In addition, and cross-correlated 2D intensities at 8.4 and 8.9 ppm in the DQ dimension associated with ${ }^{1} \mathrm{H}-{ }^{1} \mathrm{H}$ proximities between vinyl and aromatic groups of PSDVB are observed. Analyses of $2 \mathrm{D}{ }^{1} \mathrm{H}\left\{{ }^{1} \mathrm{H}\right\}$ spectra of NMDG and PSDVB spectra enable distinct 2D correlation intensities in the $2 \mathrm{D}{ }^{1} \mathrm{H}\left\{{ }^{1} \mathrm{H}\right\}$ DQ-SQ spectra of boron-adsorbed NMDG-resin to be distinguished and identified. Likewise, in the NMDG-functionalized PSDVB resin, the assignments of 2D self-correlation intensities associated with NMDG and PSDVB moieties are realized and depicted in colored gray (NMDG) and green (PSDVB) dots, which is consistent with the analyses of the $2 \mathrm{D}{ }^{13} \mathrm{C}\left\{{ }^{1} \mathrm{H}\right\}$ and ${ }^{11} \mathrm{~B}\left\{{ }^{1} \mathrm{H}\right\}$ HETCOR NMR spectra of boron-adsorbed resins discussed in the previous sections. 

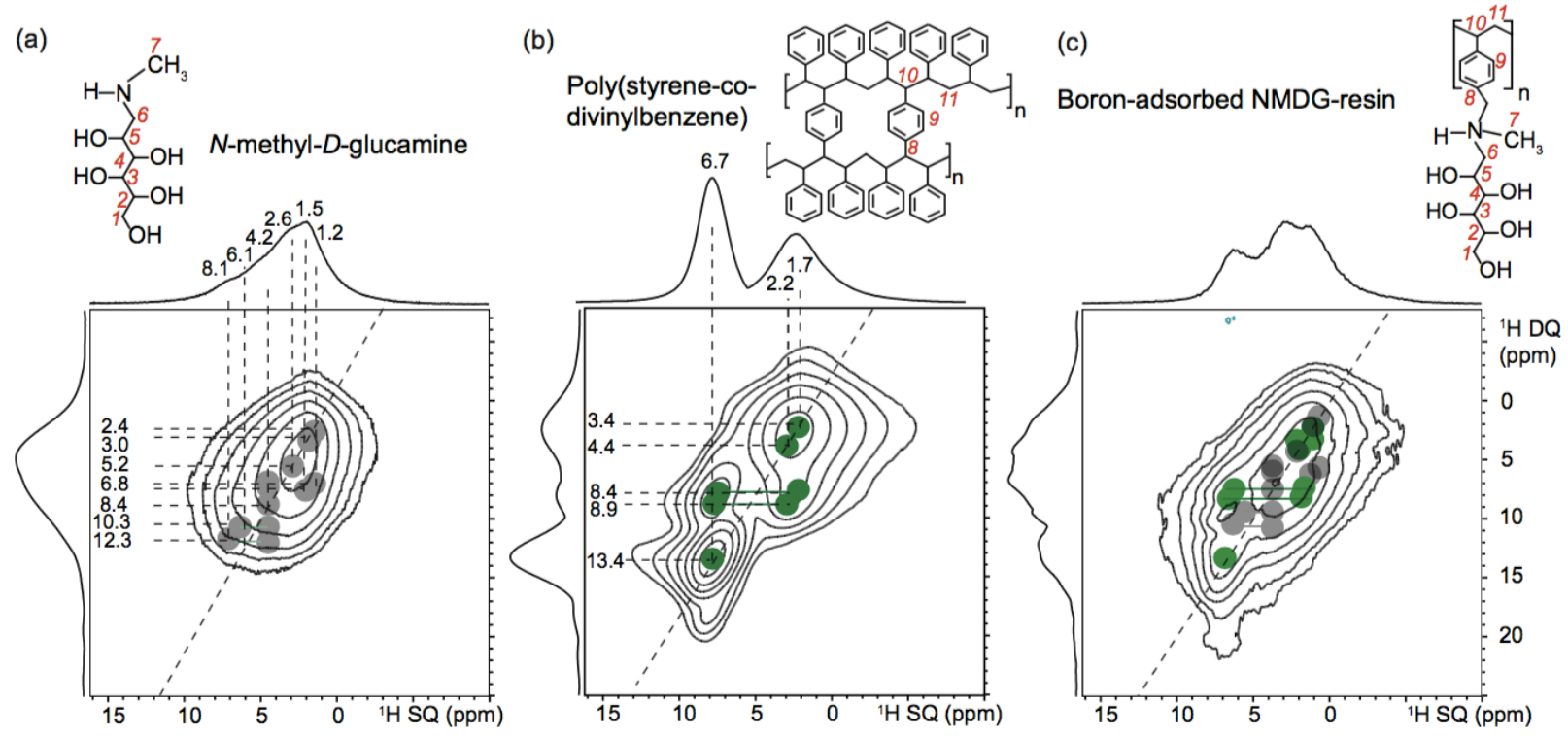

Figure S7. Solid-state $2 \mathrm{D}{ }^{1} \mathrm{H}\left\{{ }^{1} \mathrm{H}\right\}$ DQ-SQ NMR correlation spectra acquired at $11.7 \mathrm{~T}, 298 \mathrm{~K}$ and $60 \mathrm{kHz}$ MAS of (a) NMDG, (b) PSDVB resin, and (c) boron-adsorbed NMDG-functionalized PSDVB resin. The corresponding $1 \mathrm{D}^{1} \mathrm{H}$ double-quantum filtered (DQF) MAS spectra are shown along the top horizontal axes. Correlated signal intensity originates from dipolar-coupled ${ }^{1} \mathrm{H}-{ }^{1} \mathrm{H}$ pairs are depicted by gray (NMDG) and green color (PSDVB) circles.

Table S2. Experimental ${ }^{1} \mathrm{H}$ SQ and DQ chemical shifts of NMDG and PSDVB resin

\begin{tabular}{|c|c|c|}
\hline Chemical site & ${ }^{1} \mathrm{H}$ SQ (ppm) & ${ }^{1} \mathrm{H}$ DQ (ppm) \\
\hline \multicolumn{3}{|l|}{$N$-methyl- $D$-glucamine (NMDG) } \\
\hline $\mathrm{CH}_{2}+\mathrm{CH}_{2}$ & $1.2+1.2$ & 2.4 \\
\hline $\mathrm{NCH}_{3}+\mathrm{NCH}_{3}$ & $1.5+1.5$ & 3.0 \\
\hline $\mathrm{NCH}_{2}+\mathrm{NCH}_{2}$ & $2.6+2.6$ & 5.2 \\
\hline $\mathrm{NH}+\mathrm{NCH}_{3}$ & $4.2+1.5$ & 6.0 \\
\hline $\mathrm{NH}+\mathrm{NCH}_{2}$ & $4.2+2.6$ & 7.1 \\
\hline $\mathrm{NH}+\mathrm{NH}$ & $4.2+4.2$ & 9.0 \\
\hline $\mathrm{OH}+\mathrm{OH}$ & $6.1+4.2$ & 10.6 \\
\hline $\mathrm{OH}+\mathrm{OH}$ & $8.1+4.2$ & 12.6 \\
\hline \multicolumn{3}{|c|}{ Poly(styrene-co-divinylbenzene) (PSDVB) } \\
\hline $\mathrm{CH}_{2}+\mathrm{CH}_{2}$ & $1.5+1.5$ & 3.0 \\
\hline $\mathrm{CH}_{2}+\mathrm{CH}$ & $1.5+2.2$ & 3.7 \\
\hline $\mathrm{CH}+\mathrm{CH}$ & $2.2+2.2$ & 4.4 \\
\hline $\mathrm{CH}_{\text {aromatic }}+\mathrm{CH}_{2}$ & $6.8+1.7$ & 8.5 \\
\hline $\mathrm{CH}_{\text {aromatic }}+\mathrm{CH}$ & $6.8+2.2$ & 9.0 \\
\hline $\mathrm{CH}_{\text {aromatic }}+\mathrm{CH}_{\text {aromatic }}$ & $6.8+6.8$ & 13.6 \\
\hline
\end{tabular}


5. XPS analyses of NMDG-functionalized ion exchange resins with adsorbed boron for different batches

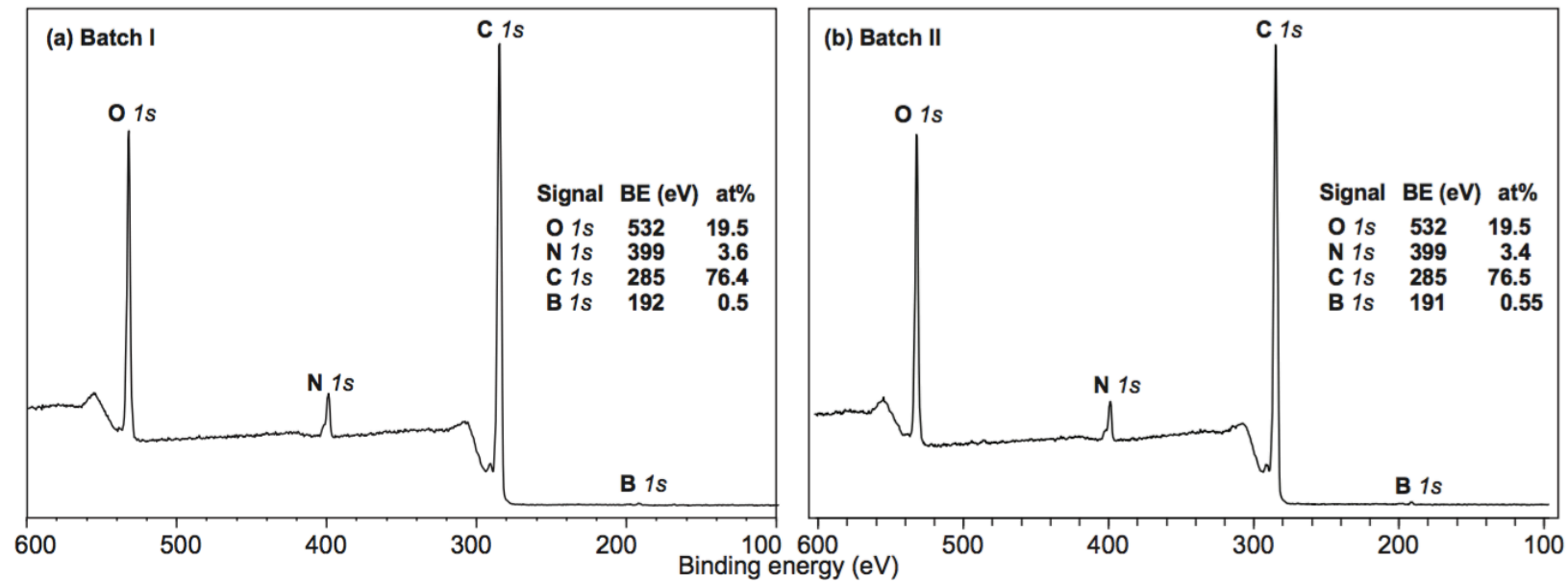

Figure S8. Survey scan XPS spectra acquired at room temperature for (a) Batch I and (b) Batch II boron-adsorbed NMDG-resins with signal intensities at 532, 399, 285 and $191 \mathrm{eV}$ assigned to O $1 s, \mathrm{~N} 1 s, \mathrm{C} 1 s$ and $\mathrm{B} 1 s$. The elemental compositions of $\mathrm{O}, \mathrm{N}, \mathrm{C}$ and $\mathrm{B}$ atoms are shown in the inset Tables and fitting parameters are given in Table S3, which depict subtle differences in the composition of $\mathrm{N}$.

Table S3. Binding energy values determined by XPS and elemental concentrations of $\mathrm{O}, \mathrm{N}, \mathrm{C}$ and $B$ atoms for Batch I and Batch II boron-adsorbed NMDG-functionalized resins.

\begin{tabular}{ccccc}
\hline Element & Binding energy $(\mathrm{eV})$ & Full width at half maximum & Area & At\% \\
\hline Batch I & & & & \\
O 1s & 532.0 & 2.52 & 10668.29 & 19.50 \\
N 1s & 399.0 & 2.34 & 1516.79 & 3.39 \\
C 1s & 285.0 & 3.01 & 19018.95 & 76.48 \\
B 1s & 191.0 & 2.13 & 70.18 & 0.5 \\
Batch II & & & & \\
O 1s & 532.0 & 2.55 & 11723.02 & 19.51 \\
N 1s & 399.0 & 2.43 & 1789.03 & 3.64 \\
C 1s & 284.5 & 2.97 & 20866.41 & 76.39 \\
B 1s & 192.0 & 2.13 & 83.33 & 0.55 \\
\hline
\end{tabular}




\section{6. ${ }^{1 D}{ }^{15} \mathbf{N}\left\{{ }^{1} \mathbf{H}\right\}$ DNP-NMR analyses of different batches of NMDG-functionalized resins}
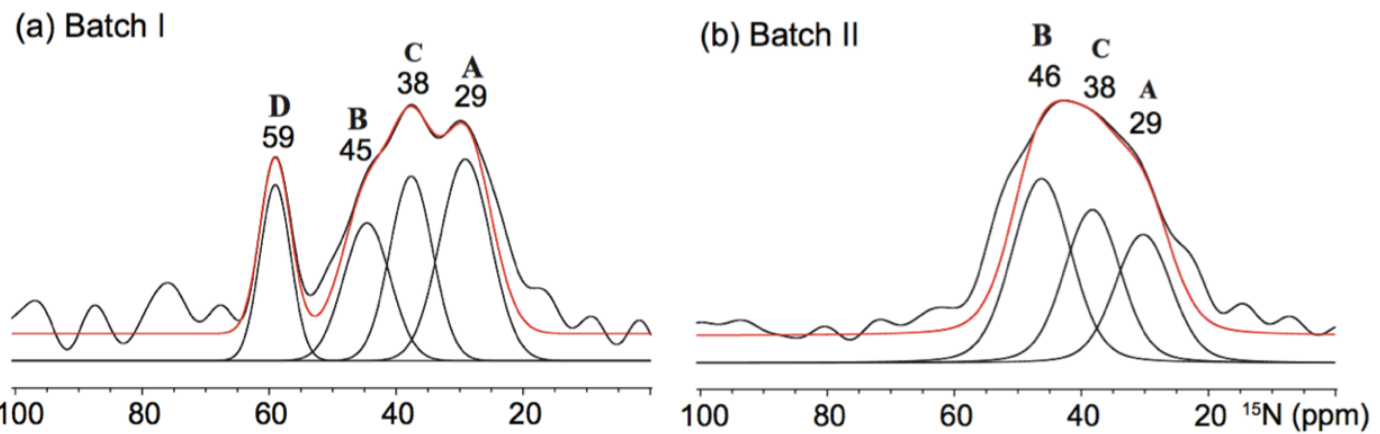

Figure S9. Surface-enhanced 1D ${ }^{15} \mathrm{~N}\left\{{ }^{1} \mathrm{H}\right\}$ DNP-MAS NMR spectra for (a) Batch I and (b) Batch II resins after boron exposure, which manifest different distributions of surface nitrogen species. The spectra were acquired at $9.4 \mathrm{~T}\left({ }^{1} \mathrm{H} 400 \mathrm{MHz},{ }^{15} \mathrm{~N} 40.6 \mathrm{MHz}\right), 92 \mathrm{~K}, 8 \mathrm{kHz}$ MAS with a CP contact time of $2 \mathrm{~ms}$ and using $16 \mathrm{mM}$ TEKPol in 1,1,2,2-tetrachloroethane.

Table S4. Deconvoluted signal integrals and lineshape analyses of surface-enhanced 1D ${ }^{15} \mathbf{N}\left\{{ }^{1} \mathrm{H}\right\}$ DNP MAS NMR spectra of NMDG-functionalized Batch I and II resins.

\begin{tabular}{lccccccc}
\hline Deconvolution parameters & \multicolumn{4}{c}{ Batch I } & \multicolumn{3}{c}{ Batch II } \\
\hline Chemical shift (ppm) & 59 & 45 & 38 & 29 & 46 & 38 & 29 \\
Gaussian broadening (Hz) & 230 & 360 & 340 & 380 & 460 & 460 & 460 \\
Normalized signal integrals (a.u.) & 1.0 & 1.2 & 1.4 & 1.9 & 1.0 & 0.7 & 0.5 \\
Densities of exchange sites $( \pm 5 \%)$ & 18 & 22 & 26 & 34 & 46 & 32 & 22 \\
\hline
\end{tabular}

7. Boron adsorption behaviors of different batches of NMDG-functionalized resins
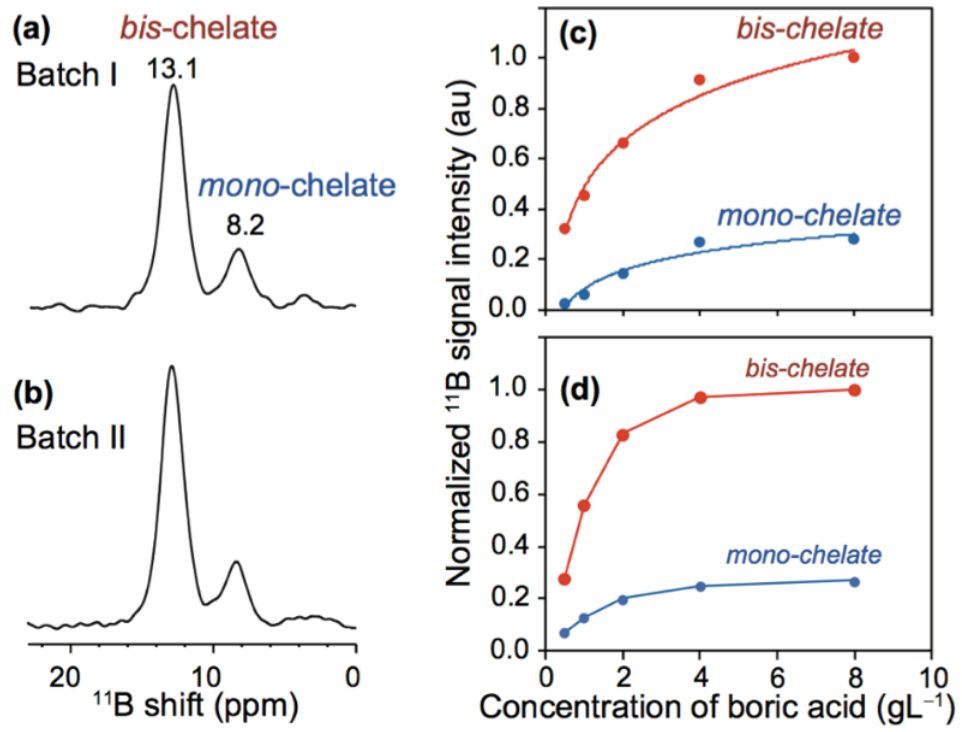

Figure S10. Solid-state ${ }^{11} \mathrm{~B}\left\{{ }^{1} \mathrm{H}\right\}$ CP-MAS NMR spectra acquired at $11.7 \mathrm{~T}, 298 \mathrm{~K}$, and $8 \mathrm{kHz}$ MAS using CP contact time of $2 \mathrm{~ms}$ for (a) Batch I and (b) Batch II boron-adsorbed NMDGfunctionalized resins. ${ }^{11} \mathrm{~B}$ signal assignments are shown for mono- and bis-chelate complexes. (c,d) Plots of normalized ${ }^{11} \mathrm{~B}\left\{{ }^{1} \mathrm{H}\right\} \mathrm{CP}$ signal intensity, as functions of boric acid concentration for (c) Batch I and (d) Batch II resins. 


\section{Solid-state 2D ${ }^{11} \mathrm{~B}\left\{{ }^{1} \mathrm{H}\right\}$ and ${ }^{13} \mathrm{C}\left\{{ }^{1} \mathrm{H}\right\}$ correlation NMR spectra of different NMDG- functionalized resins.}

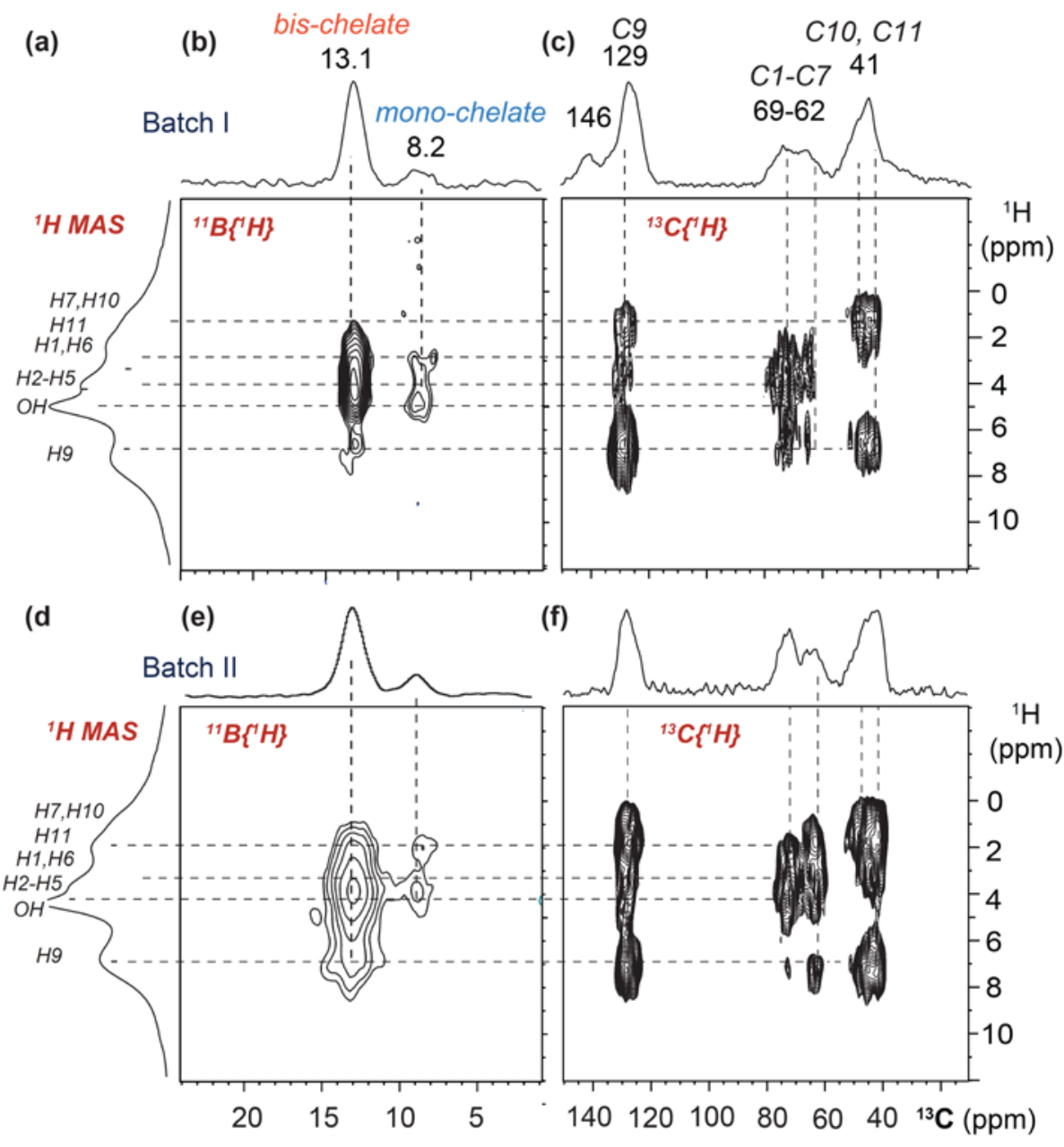

Figure S11. Solid-state 1D ${ }^{1} \mathrm{H}$ MAS NMR spectra acquired at $11.7 \mathrm{~T}$, room temperature, and 60 $\mathrm{kHz}$ MAS and 2D ${ }^{11} \mathrm{~B}\left\{{ }^{1} \mathrm{H}\right\}$ and ${ }^{13} \mathrm{C}\left\{{ }^{1} \mathrm{H}\right\}$ heteronuclear correlation NMR spectra acquired under identical conditions expect using $12.5 \mathrm{kHz}$ MAS of (top; a, b, c) Batch I and (bottom; d, e, f) Batch II boron-adsorbed NMDG-resins. 2D ${ }^{11} \mathrm{~B}\left\{{ }^{1} \mathrm{H}\right\}$ and ${ }^{13} \mathrm{C}\left\{{ }^{1} \mathrm{H}\right\}$ correlation intensities indicate the presence of mono- and bis-chelate complexes on the resin surfaces, which establish that the boron adsorption occurs through the formation of chelate complexes. 